\title{
Analysis on the Application of Post-secondary Education Discussion Teaching Method
}

\author{
Junbin Shi ${ }^{1, a^{*}}$, Chao Tu ${ }^{1, b}$, GuoBao Ding ${ }^{1, c}$ \\ ${ }^{1}$ No.1, Huayuan Road, Changchun City, Jilin Prov. China 130117 \\ a454144965@qq.com,b332552038@qq.com, c294244476@qq.com
}

Keywords: Discussion Teaching Method; Job-based education; Teaching method.

\begin{abstract}
Discussion Teaching Method is more and more used in teaching practice because it adapts to the characteristics and laws of job-based education. It is necessary to fully understand the advantages of the use of Discussion Teaching Method in job-based education, grasp the basic links and methods of the implementation of Discussion Teaching Method, deal with the three important relationships of Discussion Teaching Method practice, and continuously improve the quality and efficiency of post-secondary education-based teaching.
\end{abstract}

\section{Introduction}

On he basis of opening up the students' creativity and divergent thinking, the Discussion Teaching Method will focus on the key points, difficulties, doubts or controversial issues in the teaching, through independent study and serious thinking, and initiate class discussion, debate or communication. Teaching methods for teaching purposes. At present, the Discussion Teaching Method is more and more widely used in practice because it adapts to the characteristics and laws of post-employment education. In-depth study and exploration of how to use this method to improve the quality and efficiency of Discussion Teaching Method is of practical significance for improving the teaching level of post-secondary education institutions.

\section{Discussion-based teaching is an effective teaching method to adapt to the post education reform}

A distinctive feature of the post-secondary education reform is the emphasis on the cultivation of job responsibilities, and the Discussion Teaching Method is in line with the direction of cognitive education. The reform of the post-secondary education requires reviewing and repositioning the traditional teaching methods, and reforming the students' thinking level and the cognitive ability of the post. The traditional teaching methods focus on the theoretical teaching with depth and difficulty, but it is difficult to target the actual situation of the students. The problems faced in the work and the doubts that need to be solved are more purposeful teaching. Seminar teaching can bring the key points, difficulties and hot issues that the students pay close attention to in the actual situation and post needs of the students to the classroom, guide the students to think independently, explore exchanges, brainstorm ideas, and finally achieve the purpose of improving students' thinking level and post cognition ability.

Seminar teaching is a teaching method that adapts to the characteristics of post-employed students. Seminar teaching requires students to have the necessary basic theoretical knowledge, professional basic knowledge and certain social practical experience, so that they can analyze, discuss and discuss problems in depth, and put forward constructive opinions and ideas. The post-secondary education is targeted training on the basis of academic education. The training targets have generally completed undergraduate or postgraduate education, and have certain professional and cultural qualities. Moreover, most of the trainees are from the front line of the army. They have rich practical experience, are good at independent thinking, have a high level of 
thinking, and have their own analysis and judgment on the problem, which provides favorable conditions for conducting Discussion Teaching Method.

\section{The Discussion Teaching Method method puts forward higher requirements for the post-graduate education institutions}

First, the instructor must have a profound theoretical foundation, a broad knowledge and a keen observation ability. Teachers should be able to keep up with the current new military revolution in the world. Have a correct grasp and profound understanding of the major realities of the subject profession and the theoretical issues of the preface. The faculty carefully selects the research topics suitable for the student level, and at the same time, they must have a comprehensive understanding of the research status, existing materials and research directions of the subject. In addition, the faculty must invest a lot of time and energy to conduct full pre-investigation studies. Develop detailed seminars and track the progress of the students in time to conduct tutoring.

Second, the instructor must have a position or a job experience to understand the needs of the students. The faculty can only grasp and design the seminars in a comprehensive understanding of the subjects, and effectively apply the Discussion Teaching Method. The instructors should go deep into the army to fully understand the status of the students' job cognition and post cognition needs through the positions of appointment, agency, research, etc., and grasp the first-hand information of the army building, and have to understand the situation of the class, including the work of the students. Units, positions, educational backgrounds, work experience, etc., on this basis, establish the content of the seminar, predict the focus of the seminar process, and develop a plan for the seminar.

The third instructor must have a high level of classroom control and always have the initiative in class discussion. Seminar teaching puts forward higher requirements for the ability of educational organization guidance and classroom control. In the process of discussion, according to the trainees' discussion ideas, timely questioning and confusing, and proposing some exploratory and inspiring questions; In the event of a "cold field", the instructor can inspire the student or designate those who are more familiar and interested in the content to speak. When discussing the phenomenon of "going off the problem", the instructor should guide the participants' speech in a timely manner, and actively and effectively guide and give full play to the depth and breadth of the students' mutual influence and radiation.

\section{The basic link of rationally setting up post-employment education Discussion Teaching Method}

Seminar teaching is mainly divided into two major steps: pre-class preparation and classroom implementation.

First, the preparatory part of the class is first to determine the issue. The trainees of the post are from the front line of the army. They are learning with the problems, problems, and difficulties in the work of many troops. These problems are the most urgent and close to the actual needs of the troops. Key points, difficulties, and hot issues that need to be addressed. It is necessary to identify these problems, collect various possible situations and viewpoints in the preparation of teaching, and carefully set up seminar contents to formulate seminars. Next, a teaching preparation meeting will be held to arrange the contents of the seminar, and the program will be distributed to the trainees. According to the actual situation of the students, some discussion groups will be divided or required to be completed independently, the requirements and time limits of the seminars will be clearly defined, and the students will be informed of the ways and methods of searching for information. In the group discussion, the students who are required to be the team leader should be carefully organized, reasonably arranged and play a team spirit. Students can be required to write lectures and outlines in a certain period of time. If conditions permit, they can also produce multimedia for the lectures. At this stage, the instructors should track the progress of the students in a timely manner, understand the problems and difficulties encountered by the students during the 
research, and create for the students. Good research conditions and environment, timely counseling or individual explanation, students should communicate with each other, inspire each other and brainstorm.

Second, the classroom implementation process. Classroom implementation begins with class presentations and discussions. The seminars should be as small as possible, with about 20 students per class. Roundtable exchanges are used. According to the preparations for the seminars, classroom lectures are divided into group representative reports or individual reports. You can take a combination of keynote speeches and free speeches. It is necessary to fully mobilize the students to speak enthusiastically. The atmosphere of the class discussion is more enthusiastic. At the same time, it is necessary to control the individual speaking time. Finally, the summary summary is summarized. The summary is the sublimation of the students' discussion. It is not a simple repetition of the teaching content, or a simple synthesis of the students' speeches. Repeatedly stated, systematically, organized, and rationalized the discussion of various viewpoints and opinions, so that the students' understanding of the problem can be further extended and sublimated, and the thinking is enlightened and improved.

\section{The application of Discussion Teaching Method in job-based education must handle three relationships}

In the post-study-based teaching practice, three relationships should be handled around the focus of improving the students' thinking level and job responsibilities.

First, in the teaching ideology, we must deal with "taking the students as the main body" and "taking the teacher as the mainstay".

The relationship between the students and the students is to fully mobilize the subjective initiative of the students to enable the students to achieve independent learning, independent research, independent thinking, independent innovation, and truly improve the ability to analyze and solve practical problems. Taking the faculty as the leading factor is to organize the faculty members to be precise and guide in time, and to form a strong atmosphere conducive to the development of seminar-style teaching. Regardless of which form of research insists that the principle of openness is the most crucial, the level of discussion often depends on the degree of openness of the students' thoughts and the guidance of the instructors. It is necessary to create a relaxed and harmonious atmosphere of discussion between teachers and students, so that the students can abandon. Any form of repressive and compulsive feelings, to be enthusiastic about participating, can open up and dare to ask questions, think about problems, and explore problems.

Second, we must deal with the relationship between theoretical teaching and special discussion in teaching design. Through the top-level design, the theory teaching and the force practice should be organically combined. The basic theory of the lecture should be used to analyze the practical problems of the research force. First, the topic selection should be theoretical and should be related to the theoretical teaching part. Second, the topic selection should be targeted and should be a realistic problem facing the army building. Third, the topic selection must be deliberative, able to drive the students to think about the theoretical and practical issues, and stimulate the interest of the participants, so that the seminar will not be out of touch with the theoretical lectures, but can lead the students to the theoretical level. Deeply think about the real problems facing the construction, correctly analyze the new problems that occur in the army building, and improve the ability of the students to deal with various complex problems encountered in the work through the theory and practice.

Third, we must deal with the relationship between research and improvement of competence in the purpose of teaching. Seminar teaching closely combines research problems and analytical problems with the ability to improve the position and ability to make decisions. On the one hand, we will consolidate the theoretical frontier knowledge learned by the students, improve their level of thinking and theoretical level, and on the other hand improve their scientific decision-making and scientific management capabilities. In the teaching process, they should try to guide the participants to participate in the whole process, and work together. Improve their ability to learn, research ability, innovation ability, decision-making ability, expression ability and comprehensive ability to respond 
to emergencies. Help the students to quickly adapt to the future cognitive posts to promote the scientific development of the troops to lay a good foundation for quality and ability.

\section{References}

[1] Fang Han: Analysis on the Application of Discussion Teaching Method in College Education (military), p.20-25.

[2] Lijun Guo: An Analysis of Seminar-style Teaching Method in Vocation Education. Journal of Higher Education Research [J].Vol.34, No.2 Jun,2011.

[3] Chenbao Guo. Practice Based Deliberative Teaching in the Career-oriented Education. Journal of EEEE [J]. (2009) Vol.36, No.1 Eeb,2014.

[4] Constance Ann Mellon.Naturalistic Inquiry for Library Science: Methods and Applications for Research, Evaluation, and Teaching.Greenwood Press, 1990.

[5] Jack Zevin.Social Studies for the Twenty-First Century: Methods and Materials for Teaching in Middle and Secondary Schools.Lawrence Erlbaum Associates, 2000.

[6] Johnson, Andrew.Teacher Scandals Mirror Trend.Tribune-Review/Pittsburgh Tribune-Review, January 27, 2007. 